\title{
PRESERVATION OF TRADITIONAL CULTURE IN MODERN SOCIETY: A CASE STUDY OF CHINA MEISHAN CULTURAL PARK
}

\author{
JINGE LUO ${ }^{1,2,} \&$ FEIHU CHEN ${ }^{1,2}$ \\ ${ }^{1}$ School of Design, Hunan University, Changsha, China. \\ ${ }^{2}$ School of Architecture, Hunan University, Changsha, China.
}

\begin{abstract}
Meishan culture is one of the three ancestral Chinese cultures (the other two are the Zhongyuan and Jingchu cultures) and an important part of Huxiang history in central south China. To reproduce, preserve, and further develop a traditional Meishan culture, Meishan Cultural Park was constructed by the local residents. This paper discussed the design and construction of this cultural park in the context of cultural translation. Through cultural translations between local and ancient cultures and external and modern knowledge, a functionally modern tourism park, which reflects the traditional Meishan culture, was successfully built.
\end{abstract}

Keywords: cultural preservation, cultural translation, local culture, rural development, tourism.

\section{INTRODUCTION}

Over the course of Chinese civilization, various cultures were formed in different regions of China [1]. Recently, the protection and development of these traditional cultures have become a hot topic in the construction sector in China, especially the preservation of traditional culture through architectures or cultural parks [1-5]. In this regard, the cultural park normally serves as a carrier of the traditional culture of a certain region and also serves as a tourist site to boost the local economy. Although researches on the development of cultural heritages have been explored, they mainly focused on the regional economy, resources, and product development issues at the macro level [1, 5-7]. Therefore, more discussions on the details of cultural protection and regional economy are needed. This paper contributes to these discussions with a specific case analysis of the China Meishan Cultural Park.

The China Meishan Cultural Park was originally proposed by the local residences to preserve the precious ancient Meishan culture and to boost the local economy. Meishan culture is an ancient culture (will be introduced in details later), which has its influences in the central part of China, especially in Hunan providence. The Meishan Cultural Park is a reproduction of ancient Meishan neighborhoods and is also expected to become a famous tourism destination to boost the local economy. The research and design team of this park is led by the authors, and the team has been working on this park for a decade. The research, design, and construction of the China Meishan Cultural Park used several ways to protect traditional culture in modern society through cultural translation. This paper discusses the detailed cultural translation approach in the construction of this park.

\section{CONCEPTUAL FRAMEWORK AND METHODS}

The preservation of traditional culture by building up a cultural park is not a simple reproduction or preservation, it is however a combination of appreciating traditional culture, using contemporary techniques and boosting local economic development through a cultural translation approach. In this context, cultural translation refers to the exchanges of ideas between 
local culture and external knowledge so that a park that reflects local or traditional culture could still be a contemporary tourism destination.

The whole design process of Meishan Cultural Park involved extensively cultural translations between the design team and the local residents, and between modern ideas and ancient culture. Figure 1 illustrates the cultural translation approach in this paper.

\section{LOCAL CULTURE RECOGNITION}

The word "local" has an extremely flexible definition. A local region could as big as a nation, a culture-sphere or as small as a suburb or a village. Therefore, in practice, "local" could only be defined when comparing certain things [8]. In order to discuss local culture, the concept of the border needs to be brought in first.

\subsection{Borders of cultures}

Regional characteristics are defined by borders and orders could be then established by these borders [9]. To explore local culture, borders must be confirmed first. In the process of the formation of local culture, there is a virtual border formed based on blood, geology and religions etc. Inside this virtual border, it is easy for local people to recognize and maintain their own identities [8].

Meishan culture is one of the three ancestral Chinese cultures (the other two are the Zhongyuan and Jingchu cultures) and an important part of Huxiang history in central south China [10]. It is geographically located around the middle course of the $\mathrm{Zi}$ river in the central part of Hunan province [11]. The geographic border of Meishan culture is mainly formed because of its traffic inconvenience. Moreover, Meishan people include multiple ethnic groups such as Miao, Yao, Han, Dong and She. In the long-term historical evolutions of these peoples from different ethnic groups, Nuo culture, a unique tradition of worship, was formed. In other words, over thousands of years of evolution, Meishan culture has developed its unique characteristics with distinctive religious and humanist features, customs and art sym-

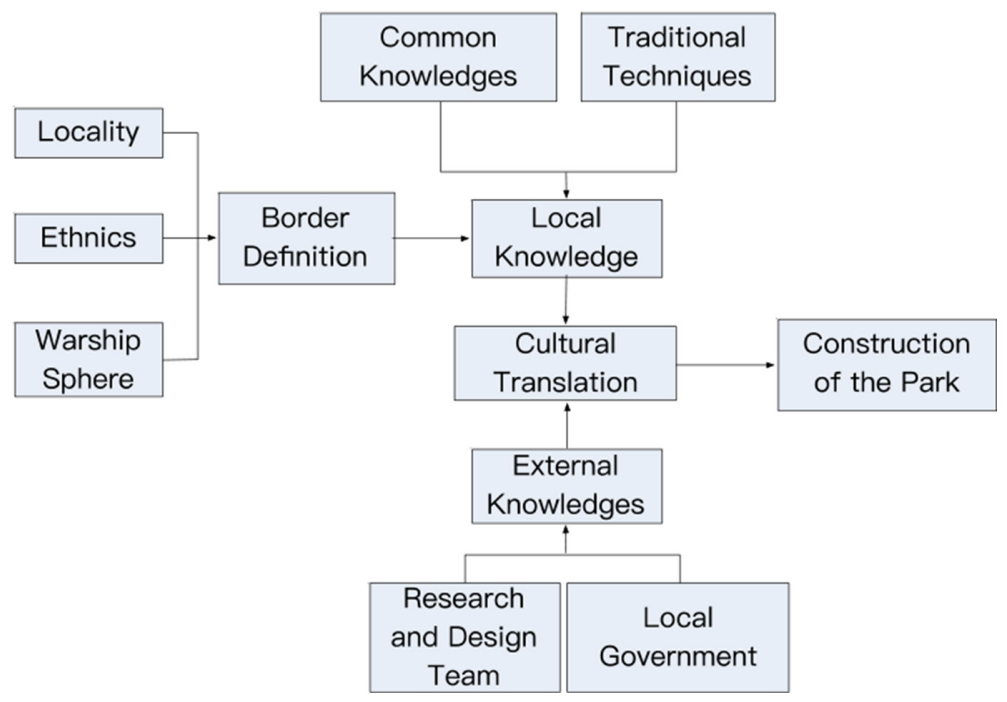

Figure 1: Illustration of cultural translation approach. 
bols. The borders of Meishan culture are based on both geography and culture. These borders give Meishan culture a unique identification, which is the basis of the Meishan Cultural Park.

\subsection{The roles of border maintaining and value addition}

Preservation of pure traditional culture (within a geographic boundary and religious sphere) is not the sole aim of the construction of the Meishan Cultural Park. More values, such as modern art forms and modern functions, should be added to the park in order to boost the present local culture and local economy.

The maintaining of authenticity and borders of traditional local culture, and adding extra values to the park could be bonded together through cultural translation. Cultural translation is, in simple words, speaking out other's interests using one's own language. Through the cultural translation, the local culture could be well displayed in the park while still adding other values into the park.

During the construction of the park, the contradiction between traditional local culture and external modern culture was effectively coordinated through cultural translation. The functional expressions of contemporary architectures were well achieved while still maintaining the features of ancient neighborhood or community. The specific ways of cultural translation will be discussed in the section below.

\section{CULTURAL TRANSLATION}

To use cultural heritages or products to attract visitors, the products must be authentic [12, 13]. However, the authenticity of attractions should be "staged" to meet the needs of the modern tourist industry $[14,15]$. The design of the Meishan Cultural Park followed this rule through cultural translation to create a "staged authenticity" [16] of the Meishan culture. Specifically, an attempt was made to "copy" the original Meishan culture first; then the copy was modified to meet the requirements of the modern society. The approaches of creating staged authenticity using cultural translation are discussed below in details.

\subsection{Preservation: translate local and ancient culture to contemporary design practices}

Preserving the consistency of architectural symbols and maintaining the stability of spatial orders is the first step to create a staged authenticity of Meishan culture.

\subsubsection{Preservation of architectural symbols}

Architectural symbols are the most intuitive perceptions of local traditional culture. In the construction of the Meishan Cultural Park, continuation of architectural symbols was achieved through the process of extraction and reorganization of the genes of local architectures. Local building materials and construction methods were used, which have brought valuable strengths to these modern architectures in the park. The extractions of architectural symbols were based on extensive research on the traditional culture, on the proper use of local wood, stone, clay, brick, tile, bamboo, grass and other building materials, and on the reorganization of traditional building methods and skills. Through these ways, a prototype of an ideal community of Meishan region was constructed. In this context, architectural symbols can be divided into two categories: individual buildings and building components.

Individual buildings, as architectural symbols, need to reflect the culture of generations of Meishan residents and imprints of the integrations of multiple ethnic groups. The symbols of 
many traditional architectural types of Meishan region have been extracted and integrated in various buildings of the park. Specifically, the park contains: (1) Han Chinese residential buildings such as quadrangle courtyard; (2) shelter bridges with a blend of architectural features of minority groups of Miao, Yao and Dong; (3) tower buildings such as Jingpai tower and Wenchang pavilion, which featured several minority groups' culture; (4) Chinese black tea stores, tea pavilions, and grain mill facilities, which all represent the ancient Meishan local industries; (5) watchtowers and Meishan posts which reproduced the defense infrastructure of ancient Meishan villages.

Besides individual buildings, the architectural symbols of building components, which include the details of these architectures, are equivalently important. The building components that represent the Meishan culture include: (1) Fenghuo wall (i.e. fire wall), which is a typical representative of the traditional Meishan architecture; note that the present Fenghuo walls in the park only serve as ancient architectural symbols while their actual function was not preserved; (2) Ox horn, which has been recognized as a fetish by ancient Meishan people were decorated on Fenghuo walls, roofs and door shafts etc. in the park; these Ox horns represent the worship symbols of ancient Meishan people - people believe that these Ox horns can drive away evils and maintain peace; (3) Column bases were collected from various abandoned ancient buildings in the Meishan region and arranged in arrays in the park; these bases also serve as functional components that protecting these wooden structures from been eroded.

\subsubsection{Continuity of spatial orders}

The combinations of all these architectural symbols above obey certain laws and rules, which is called the spatial orders of architectures. Spatial orders of architectures were established based on social activities, culture, and social values in a certain region. These spatial orders represent the connections among peoples and connections between people and the environment. In this context, the continuity of spatial orders of the cultural park is to preserve the spatial organizations of traditional Meishan communities. Specifically, the buildings in the park were all on terraces and gentle slopes along the road and water systems based on the spatial orders of spontaneous-generated villages in this region. These buildings used traditional local building materials and scattered in the mountains, which reflect the simple and unsophisticated worldviews of Meishan people - harmony between people and nature. The continuity of spatial order falls into two different levels: the site selections of the whole park and the space orders of individual buildings.

The principles of park site selection are inconsistent with the ideal Feng Shui rules of ancient Meishan people, which is facing onto the water and backing onto the shadowy side of a mountain. The site of the park is enclosed by mountains, which is exactly the same as many locations of ancient Meishan villages. Ancient Meishan villages were normally located at steep mountains, which make them easier for defense. In addition, all residential buildings in the park were based on the features of typical traditional residences and were slightly adjusted according to their specific terrain and functions. Therefore, the continuities of spatial orders were highly preserved through this way of site selection.

The spatial orders of individual buildings were also well preserved by reproducing the key features of traditional Meishan houses. For instance, the spatial orders a small farmhouse in the park were designed to be similar to an ancient house (Liao Zhai Tang) in Anhua county [17] (Figs 2 and 3). The highest degrees of similarities of these two were found in the spatial arrangements, spatial partition and spatial streams [18]. Specifically, all residential buildings used courtyard as the core of the whole house. The living spaces all followed the order of "common room - central room - common room" and the central room is the key space that 
bonds all the living spaces together. In Meishan region, a central room is generally the spaces where spiritual functions exist; these functions include worship, weddings, funerals and reception of guests etc.

4.2 Renovation: building ancient architectures based on contemporary design practices

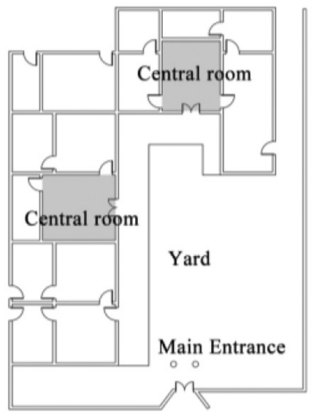

Layout of an ancient house in Meishan region

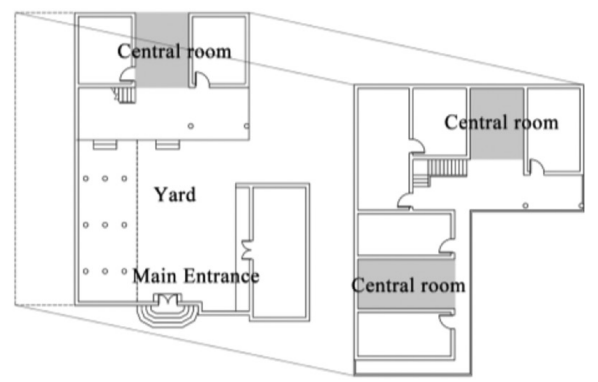

Layout of a house in the park

Figure 2: Comparison of an original local residence and a park building.
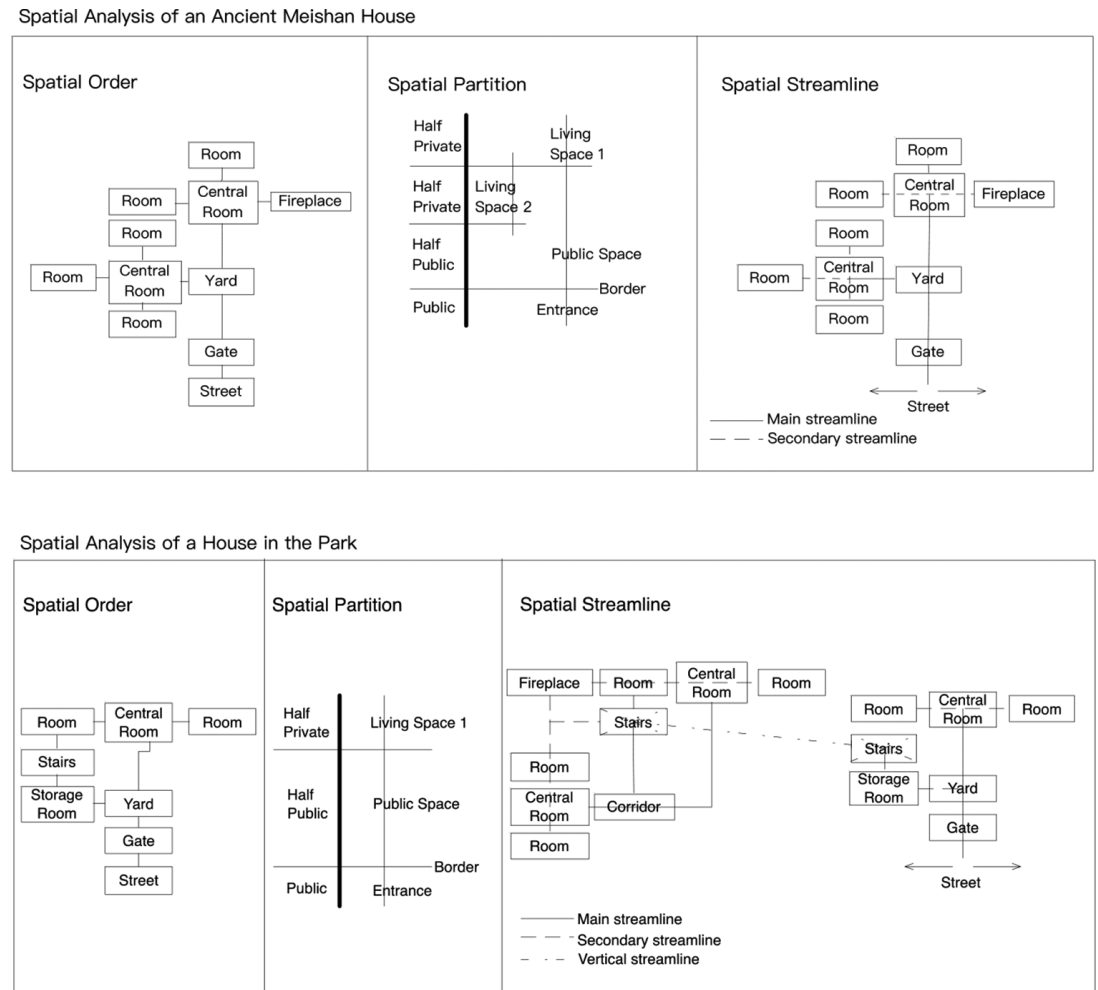

Figure 3: Comparisons of the spatial orders of a local house with a park house. 
The preserved culture and architectural features need to be renovated to meet the requirements of the modern society, which is the second step to create a staged authenticity of Meishan culture. Renovation in the context of cultural translation involves the translation of modern knowledge (i.e. contemporary design requirements and practices) into proper traditional architectural features that are in line with local culture and could be recognized and appreciated by local and external people.

\subsubsection{Renovation of various functional spaces}

Meishan Culture has an extreme long history. The region has 15,000 years of history and the culture was shaped before 500 AD [19]. Although Meishan culture exists in a very long period of time, it does not mean that it is static. Many functionally modern facilities with ancient features at various historical periods were built in the park. The architectural styles in the park, including local neighborhood, street and modern functional spaces, demonstrate different stages of Meishan culture.

The buildings in the park were all renovated from ancient building styles. Specifically, the display and experiencing spaces (buildings), including Meishan Museum, Meishan Witchcraft House and Meishan Kongfu House, were all functionally modern buildings with ancient Meishan architectural styles. The service spaces, including accommodation and catering facilities, were based on stilt buildings (Fig. 4). Mei Yi Village (i.e. Meishan craft village), Meishan academic centers, reception centers and the artist village were constructed to educate visitors regarding to Meishan history and culture. A few Meishan cultural and academic research bases were also constructed, which include teenagers education base, university student internship base, film base and cultural industrial park.

The renovations of all buildings are through combinations of many possible functions and architectural styles. The same function could be achieved in different architectural forms [20]. For instance, the corridor arch structure of the Meishan museum is inspired and borrowed from the ancient Meishan kiln. However, the yard is totally different from traditional courtyard. The water added to the yard strengthened the spatial characteristics of the courtyard, highlighted the "quiet" functional demands of the museum, "clean" space, and the "mirror" of the artistic conception (Figs 5 and 6).

\subsubsection{Renovation based on low impact development strategies to achieve sustainable development}

In the past decades, concerns about environmental quality, economic development and the threat of climate change have converged to produce a growing interest in the concept of

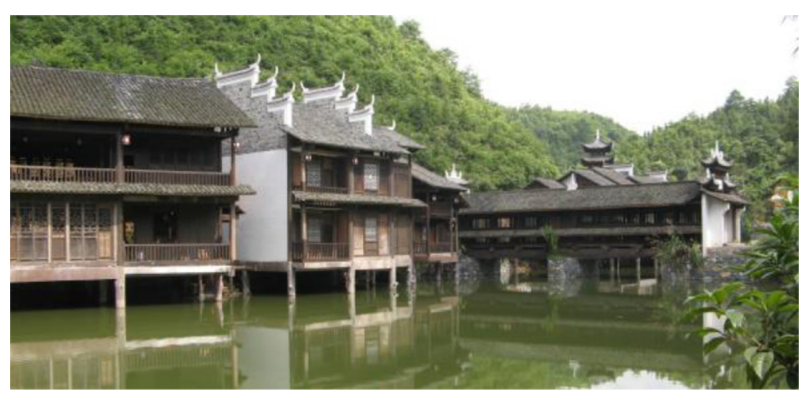

Figure 4: Diaojiao buildings (i.e. stilted buildings) of the Meishan Cultural Park. 
sustainable development [21-23]. In 1987, the United Nations World Commission on Environment and Development coined and defined the meaning of the term "Sustainable Development" [24] as: "...development that meets the needs of the present without compromising the ability of future generations to meet their own needs". After that, sustainability has quickly been transformed into a much broader concept. Low impact development design is one of many approaches to achieve sustainable development.

Low impact development was piloted in Maryland, Prince George's County, United States in 1999 as a way to mitigate the negative effects of increasing urbanization [25]. It emphasizes the reduction of impacts on the environment during the urban construction and development process [26]. It could be achieved by the rational use of landscape spaces [27], control of storm water runoff [28,29], building of natural-adaptive drainage system and other initiatives ways. These low-impact development concepts are now mainly used in urban development. Here, the idea of low-impact development was incorporated into the design and construction process of the cultural park, especially regarding to the greening design and drainage system design.

At the planning stage of the park, the intensity of development was determined by the idea of "wild weed will still be growing and wild flowers will still be flourishing". Since these wild plants can grow by themselves, it reduces the cost of maintenances and also prevents the local species from being destroyed by foreign species [30]. Besides the original in situ wild plants, other new plants that introduced into the park were all local plants. These plants were carefully selected and blended together according to four seasons, which enriches the original in situ plants and exhibits good seasonal changes of the park. A large

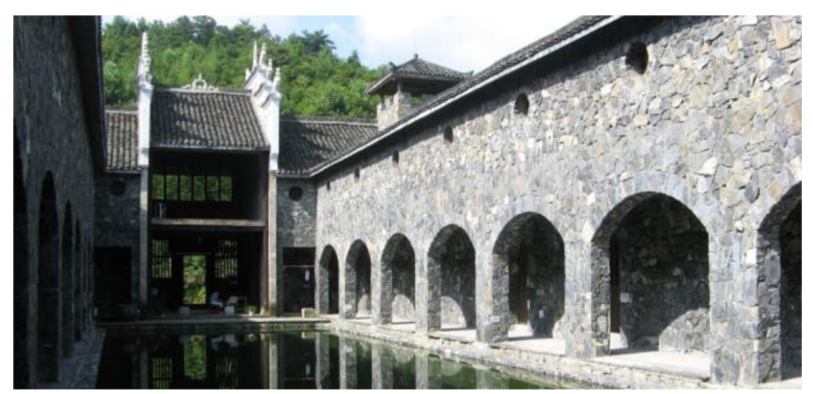

Figure 5: Yard of the Meishan museum.

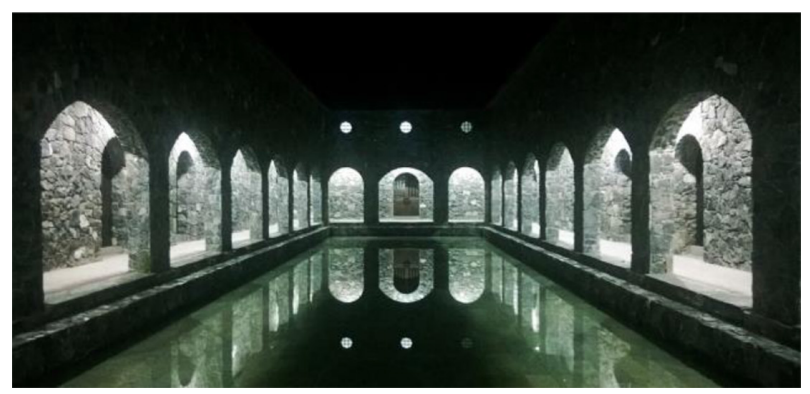

Figure 6: Inner court of the Meishan museum. 
amount of catalpa and bamboo also serves as building materials at the beginning of the construction.

Ground pavement and rainwater collection are two factors that affect the drainage management system. The roads inside the park are mainly walking trails, thus high permeable material need to be used to allow quick dry of these trails after rain. In the park, most of the roads are gravel compacted surface. Those roads along the Diaojiao building (i.e. stilted building) were paved with quartzite, which shows the ancient commercial cultural atmosphere. Both the gravel and quartzite were paved without using any adhesive material, they were however directly paved on top of the original soil which allows the rainwater to be quickly returned to natural circulation system. Meishan region is rich in bamboo; therefore bamboos were used as drainage pipelines. A portion of the rainwater is collected and transported through these bamboo pipelines to reservoirs for processing and future use.

\section{CONSTRUCTION ACHIEVEMENTS}

As one of the three ancestral Chinese cultures, Meishan culture was not well preserved before. Meishan cultural park was the first attempt to preserve these precious culture. The first stage of the design and construction of this park has finished and the second stage is still going on and is listed as a key project in the Tourism Development Plan of Anhua County 2014-2030. The total investment will be 200 million Chinese Yuan (about 31 million US Dollars). This park is projected to receive about 300,000 of visitors per year once the construction was fully completed. The construction of the park not only benefited local residents economically, but also inspired local residents to rethink their culture and bring a sense of pride for their culture. More importantly, the location of the park allows poor people to participate directly, which is in line with the poverty relief strategies that shaped by China central government.

Although the construction is still going on, more than 20 universities (domestic and international) have established their educational bases in the Meishan cultural park. These universities include Hunan University, Central South University, Hunan Normal University, Louisiana State University, and School of Architecture in Nancy, France etc.

\section{CONCLUSIONS}

Strong local cultures developed over the course of Chinese civilization provide a rich ground for the development of cultural heritage tourism products. However, these local cultures need to be translated to a modern functional tourism product through cultural translation. The construction of the China Meishan Cultural Park is a practice of using this cultural translation approach. A functionally modern tourism park with ancient building symbols and culture was successfully built. It also shows that a relatively strong collaboration between the local residents and design team in the construction of these cultural parks is necessary for similar projects. It is believed that the ways of cultural translation discussed in this paper are able to shed light on the protection and development of local culture in other regions.

\section{REFERENCES}

[1] Li, Y., Exploring community tourism in China: the case of nanshan cultural tourism zone. Journal of Sustainable Tourism, 12(3), pp. 175-193, 2004. http://dx.doi.org/10.1080/09669580408667232

[2] $\mathrm{Wu}, \mathrm{L} .$, Borrowing the brilliance of the famous painting to bring out the splendid landscape-a rustic opinion on the que and hua mountains historical and cultural park in Jinan. Chinese Landscape Architecture, 2006(1), pp. 1-6, 2006. 
[3] Wang, X., Ideas on Zhenghe park design: the integration of history, reality and future. Forest Inventory and Planning, 2005(3), pp. 19-21, 2005.

[4] Lu, M., Cheng, Z. \& Wang, J., Harmony between urban park regional culture and modern life:landscape planning and designing on Yanzi park. Journal of Shandong Jianzhu University, 2009(2), p. 95, 2009.

[5] Gao, S., Huang, S. \& Huang, Y., Rural tourism development in China. International Journal of Tourism Research, 11(5), pp. 439-450, 2009. http://dx.doi.org/10.1002/jtr.712

[6] Ye, L., Review essay: tourism and china's development: policies, regional economic growth and ecotourism; tourism in china; tourism and hotel development in china: from political to economic success. Journal of the American Planning Association, 74(1), pp. $150-151,2008$. http://dx.doi.org/10.1080/01944360701755923

[7] Dredge, D., Development, economy and culture: cultural heritage tourism planning, liangzhu, china. Asia Pacific Journal of Tourism Research, 9(4), pp. 405-422, 2004. http://dx.doi.org/10.1080/1094166042000311273

[8] Yang, H., From the perspective of local knowledge and indigenous category. Thought \& Words, 49(4), pp. 5-29, 2011.

[9] Hara, H., 100 Teachings from the Settlements in the World, China Building Industry Press: Beijing, 2003.

[10] Zhang, L., Landscape diachrony in the design expression for meishan culture park: a survey. Journal of Asian Architecture and Building Engineering, 13(1), pp. 157-162, 2014.

http://dx.doi.org/10.3130/jaabe.13.157

[11] Luo, J., Symbolic representation of indigenous architectures in meishan region. Applied Mechanics and Materials, 357-360(1), pp. 168-171, 2013.

http://dx.doi.org/10.4028/www.scientific.net/AMM.357-360.168

[12] Taylor, J., Authenticity and Sincerity in Tourism. Annals of Tourism Research, 2001(28), pp. 7-26. http://dx.doi.org/10.1016/S0160-7383(00)00004-9

[13] Waitt, G., Consuming heritage. Perceived historical authenticity. Annals of Tourism Research. 2000(27), pp. 835-849, 2000.

http://dx.doi.org/10.1016/S0160-7383(99)00115-2

[14] Bruner, E., Transformation of self in tourism. Annals of Tourism Research, 1991(18), pp. 238-250.

http://dx.doi.org/10.1016/0160-7383(91)90007-X

[15] Chhabra, D., Healy, R. \& Sills, E., Staged authenticity and heritage tourism. Annals of Tourism Research, 30(3), pp. 702-719, 2003.

http://dx.doi.org/10.1016/S0160-7383(03)00044-6

[16] MacCannell, D., Staged authenticity: arrangements of social space in tourist settings. American Journal of Sociology, 79(3), pp. 589-603, 1973. http://dx.doi.org/10.1086/225585

[17] Zou, Y., Anhua Traditional Architecture with Meishan Culture, Hunan Univeristy: Changsha, 2008.

[18] Duan, J., Ji, S. \& Wang, H., Spatial Analysis of Architectures in Ancient Towns in Lake Tai Vally. Beijing: China Building Industry Press, 2002.

[19] Zhang, S., Unveil the Mysteries of Meishan Culture. Journal of Yiyang Teachers College, pp. 64-66, 1998. 
[20] Lu, J., Architectural regionalism in spontaneous building. Journal of Architecture, (1), pp. 49-54, 2009.

[21] Deakin, E., Sustainable development and sustainable transportation: Strategies for Economic Prosperity, Environmental Quality, and Equity, 2001.

[22] Hopwood, B., Mellor, M. \& O'Brien, G., Sustainable development: mapping different approaches. Sustainable Development, 13(1), pp. 38-52, 2005. http://dx.doi.org/10.1002/sd.244

[23] Sepe, M., Improving sustainable enhancement of cultural heritage: smart placemaking for experiential paths in pompeii. International Journal of Sustainable Development and Planning, 10(5), pp. 713-733, 2015.

http://dx.doi.org/10.2495/SDP-V10-N5-713-733

[24] WCED, Our Common Future, Oxford University Press: Oxford, 1987.

[25] Dietz, M.E., Low impact development practices: a review of current research and recommendations for future directions. Water, Air, and Soil Pollution, 186(1), pp. 351-363, 2007. http://dx.doi.org/10.1007/s11270-007-9484-Z

[26] Ahiablame, L.M., Engel, B.A. \& Chaubey, I., Effectiveness of low impact development practices: literature review and suggestions for future research. Water, Air, \& Soil Pollution, 223(7), pp. 4253-4273, 2012. http://dx.doi.org/10.1007/s11270-012-1189-2

[27] Davis, A.P., Green engineering principles promote low-impact development. Environmental Science \& Technology, 39(16), pp. 338-344, 2005. http://dx.doi.org/10.1021/es053327e

[28] Chang, N., Hydrological connections between low-impact development, watershed best management practices, and sustainable development. Journal of Hydrologic Engineering, 15(6), pp. 384-385, 2010.

http://dx.doi.org/10.1061/(ASCE)HE.1943-5584.0000236

[29] van Roon, M., Water localisation and reclamation: Steps towards low impact urban design and development. Journal of Environmental Management, 83(4), pp. 437-447, 2007. http://dx.doi.org/10.1016/j.jenvman.2006.04.008

[30] Zhang, L., The Research of Low Impact Environment Development Design Strategies of Tourism Culture Resources in Meishan Region: Changsha, Hunan Univeristy: Changsha, 2013. 